\title{
Educadoras Sanitárias e Enfermeiras de Saúde Pública: identidades profissionais em construção*
}

\author{
Lina Faria**
}

\begin{abstract}
Resumo
Este é um estudo sobre a história das educadoras sanitárias e das enfermeiras de saúde pública na primeira metade do século XX, em São Paulo. Tem por objetivo mostrar o desafio, às mulheres, de demarcar um território de decisões e atuação que não fosse simples "poder delegável" pela profissão médica. A sociologia histórica (no tocante às relações entre instituições, poder $e$ identidades profissionais) proporcionou um instrumental teórico $e$ metodológico para o presente trabalho. Entre as conclusões, destacamos a importância do surgimento de um novo campo profissional, relacionado à educação sanitária e à enfermagem de saúde pública. O texto destaca, brevemente, a participação da Fundação Rockefeller na organização do campo de saúde pública, uma vez que a Rockefeller apoiou a valorização do papel da mulher educadora e enfermeira em São Paulo, com recursos humanos e financeiros.
\end{abstract}

Palavras-chave: Mulheres Educadoras, Mulheres Enfermeiras, Identidade Profissional, Saúde Pública.

\footnotetext{
" Recebido para publicação em abril de 2005, aceito em setembro de 2005. Este trabalho faz parte de um conjunto de estudos, que Luiz Antonio de Castro Santos e eu dirigimos na Uerj e na Unicamp, sobre a formação histórica da saúde pública no Brasil. Um agradecimento especial é devido a Maria Teresa Citeli, cuja leitura atenta de uma versão anterior e inúmeras sugestões foram de imensa ajuda.

*** Pós-doutoranda no Depto. de Política Científica e Tecnológica, Instituto de Geociências/Unicamp. lfaria@ige.unicamp.br
} 
Educadoras Sanitárias e Enfermeiras

Health Educators and Public Health Nurses:

Professional Identities in the Making

\begin{abstract}
This is a study about São Paulo's health educators and public health nurses in the first half of the $20^{\text {th }}$ century. These were occupations designed for women, who faced difficult challenges trying to demarcate a territory of decision and action that did not result solely from the medical profession's "benevolence" toward them. The tools of historical sociology contributed, both theoretically and methodologically, to an appraisal of the relationships between institutions, power, and professional identities. Among the main conclusions, this article reveals the importance of the rising of a new professional field in health education and public health nursing. In addition, the work calls attention to the role played by the Rockefeller Foundation in opening up these new occupational tracks. The Foundation's officers payed close attention to the setting of working conditions for the young professionals, helping them with human, technical, and financial resources.
\end{abstract}

Key Words: Female Health Educators, Female Nurses, Professional Identities, Public Health. 
Lina Faria

\section{Introdução}

Em função da falta de enfermeiras graduadas em São Paulo, até aproximadamente a segunda metade dos anos de 1940, as autoridades sanitárias deram preferência à formação de educadoras ou "visitadoras". Ao contrário do que acontecia nos Estados Unidos, o número reduzido de profissionais de saúde pública (diplomadas pela Escola Anna Nery, criada em 1923) praticamente impossibilitava a atuação dessas profissionais em escala nacional. O primeiro curso de Educação Sanitária foi criado, então, em 1925, no Instituto de Higiene de São Paulo embrião da atual Faculdade de Saúde Pública da Universidade de São Paulo. Só em 1942, seriam criados o Serviço de Enfermagem do Instituto de Higiene e a Escola de Enfermagem da Universidade de São Paulo. O Curso de Educadoras Sanitárias teve grandes percalços, a partir da implantação da Escola de Enfermagem na Universidade de São Paulo. Logo vieram à tona questões de hierarquia profissional e competência técnica. Com o passar dos anos, a liderança profissional das enfermeiras diplomadas tornou-se incontestável e as educadoras eram vistas como enfermeiras "informais", como se lhes faltasse um treinamento profissional de peso.

Baseado em pesquisa bibliográfica e em entrevistas com educadoras sanitárias, o trabalho discute o papel dos centros de saúde na formação dessas profissionais e na construção de uma identidade profissional "feminina" para esse novo campo de atuação - que se ampliará, mais tarde, com a profissionalização da enfermagem. Fundamentadas na higiene, as ações dos centros de saúde abrangiam medidas profiláticas de controle das doenças infecciosas, a educação sanitária e o treinamento de profissionais de saúde pública. A formação de novas categorias - educadoras e enfermeiras - seguiu um modelo de profissionalização baseado na "feminização" da atenção ao paciente e às famílias.

O debate sobre a formação do campo da enfermagem, como profissão "feminina", remete diretamente aos pressupostos 


\section{Educadoras Sanitárias e Enfermeiras}

tradicionais sobre o gênero, desde o século XIX. Segundo Leibowitz (1975:20-35), as diferenças de anatomia entre homens e mulheres foram, durante séculos, interpretadas como intimamente relacionadas às diferenças nas capacidades emocionais $e$ intelectuais, bem como em relação às habilidades físicas. Nesse sentido, as tarefas e os papéis designados para homens e mulheres na sociedade tinham como base estas aptidões. Segundo a autora, a visão da anatomia humana como "destino" estava presente nos debates científicos até meados do século XX. De fato, esse ponto de vista foi recorrente entre as primeiras lideranças da Enfermagem Moderna, particularmente na Europa. O pensamento de Florence Nightingale - considerada a fundadora da Enfermagem Moderna -, nesse sentido, é bem conhecido. "O cuidar dos doentes é uma tarefa que sempre coube à mulher $e$ sempre lhe deve caber". (apud Chagas, 1922:5) ${ }^{1}$

A mulher enfermeira projetou-se para o interior do mundo das profissões emergentes do século $\mathrm{XX}{ }^{2}$ Tanto a profissão da enfermagem quanto o predomínio quase exclusivo ali conquistado se constituem a partir das primeiras décadas do século passado. Mesmo quando assumia ofícios que se somavam às atividades familiares - como a produção artesanal ou o trabalho assalariado - o trabalho feminino era ainda fundamentalmente restrito ao

\footnotetext{
1 Ver, ainda, História da Enfermagem. Personalidades. www.hospvirt.org.br/ enfermagem/port/personalidades. Acesso em 10 de maio de 2005.

2 Em artigo sobre a formação de enfermeiras em São Paulo, Maria Lúcia Mott faz uma crítica à bibliografia que trabalha com o tema. Segundo a autora, a literatura vinha considerando a enfermagem como uma profissão feminina "desde sempre", em virtude de "o cuidar da família, dos doentes e das crianças" ser um papel desempenhado tradicionalmente pelas mulheres, uma extensão das atividades domésticas. Mott mostra em seu trabalho que, no final do século XIX, a enfermagem era uma profissão exercida tanto por homens quanto por mulheres e cita o exemplo do Hospital da Caridade da Santa Casa de Misericórdia de Salvador. Segundo a autora, a mudança de perfil profissional se dá na virada do século XX com o advento da "enfermagem moderna", quando as discípulas de Florence Nightingale começaram a assumir papéis que antes eram desempenhados pelos homens. Ver Mott, 1999:327-355.
} 
ambiente doméstico até o início da industrialização européia. É verdade que há bem pouco tempo a enfermagem era conhecida por algumas correntes da sociologia como "quase-profissão" (cf. Freidson, 1975) em razão da falta de autonomia ou da subordinação a outros profissionais, mas também é verdade que as discípulas de Florence Nightingale começaram a assumir papéis antes desempenhados pelos homens. Numa luta que teve lugar especialmente nos Estados Unidos - onde, diferentemente da Inglaterra, as enfermeiras cedo criaram suas próprias organizações profissionais e faziam o recrutamento em bases mais abrangentes do que as "well-born ladies" educadas nos hospitais de Londres a enfermagem, particularmente a enfermagem de saúde pública, permitiu às novas profissionais conquistarem espaços de autonomia e legitimidade diante da hierarquia médica. (Davies, 1983)

Florence Nightingale organizou, em 1859, o primeiro Curso de Treinamento para Enfermeiras em Londres, no Hospital São Thomaz. Lá demonstrou, "o valor da enfermeira inteligente e habilitada, abrindo caminhos à mulher para servir à humanidade". Depois do estabelecimento dessa primeira escola, outras foram organizadas não só na Inglaterra, mas nos Estados Unidos e em outros países.

$\mathrm{E}$, onde quer que um tal programa tenha sido bem concebido e bem executado nunca deixou de atrair grupos de mulheres, que estabeleceram tradições de elevados ideais e de devotamento profissional. (Chagas, 1922:1-10)

No início do século XX, havia nos Estados Unidos cerca de 100 mil enfermeiras trabalhando nas mais diversas especialidades e cerca de 50 mil alunas inscritas nas 1.585 escolas registradas. ${ }^{3}$

${ }^{3}$ Uma grande proporção dessas escolas, do mesmo modo que no campo da medicina, estavam abaixo dos níveis profissionais que seriam adotados, neste último campo, após o Relatório Flexner e, na enfermagem, em decorrência das críticas feitas no Relatório Goldmark, de 1923. Ver Goldmark, 1923. 
Educadoras Sanitárias e Enfermeiras

Essa mudança de perspectiva em relação ao sexo feminino deve ser entendida, segundo Paicheler (1995:5-10), como parte de um conjunto de transformações sociais, políticas, culturais $e$ econômicas, onde a mulher passa a assumir papéis antes reservados aos homens. $\mathrm{Na}$ França, segundo Schultheiss (2001:126), eram grandes as resistências entre os enfermeiros à atuação da mulher nos hospitais. Para eles, a "feminização" da enfermagem traria desprestígio a profissão.

A entrada mais efetiva da mulher no mercado de trabalho foi possível em virtude das mudanças que vinham ocorrendo no mundo desde final do século XIX. Além disso, a rígida diferenciação de papéis sociais, atribuídos aos homens e às mulheres, já não canalizava os novos rumos e comportamentos sociais. (Paicheler, 1995:5-6) Neste cenário de transformações do papel feminino na sociedade - tanto nos Estados Unidos como em países europeus, principalmente Inglaterra e França -, as primeiras mulheres a atuarem no campo científico e profissional representaram um papel importante nos debates sobre a natureza da sexualidade feminina. O momento era de grandes mudanças e disputas. Por um lado, as visitadoras sanitárias e as enfermeiras, que ganhavam cada vez mais o reconhecimento público. Por outro, a entrada da mulher na medicina. ${ }^{4} \mathrm{~A}$ oposição à entrada de

\footnotetext{
${ }^{4}$ No Brasil, Maria Augusta Generoso Estrela foi a primeira mulher a se formar em Medicina, em 1881. Estrela Generoso exerceu importante influência nos debates travados pela intelectualidade do século XIX que levaram D. Pedro II a assinar a Reforma Leôncio de Carvalho. Esta reforma abriu as portas do ensino superior às mulheres brasileiras. Nos Estados Unidos, a médica Elizabeth Blackwell foi uma das primeiras a romper com a tradição que excluía as mulheres da medicina, no espaço hospitalar. Blackwell foi responsável pela criação, em meados do século XIX, do primeiro hospital dirigido por mulheres - New York Infirmary for Women and Children. Lá, as médicas formadas faziam suas residências, uma vez que lhes eram negadas por todos os hospitais dos Estados Unidos. A proposta de Blackwell era tentar combater os abusos médicos, além de oferecer um tratamento mais específico às doenças femininas e, principalmente, promover a educação da mulher, a partir do conhecimento do seu próprio corpo. Ver Rago, 2000:199-225.
} 
mulheres nesse campo era muito forte entre os médicos. Apesar de iniciativas pioneiras como de Louise Bourgeois - que escreveu manuais sobre temas ligados à mulher - foram os homens, que, segundo Rohden, inauguraram, na medicina, os rudimentos da obstetrícia e ginecologia modernas. (Rohden, 2001:46) No entanto, o surgimento de uma "medicina da mulher", a criação de novas maternidades, hospitais, dispensários e enfermarias, no final do século XIX e início do $\mathrm{XX}^{5}$, abriria caminhos para essas mulheres dispostas a enfrentar as hostilidades dos médicos, mas, principalmente, dispostas a demarcar um território de decisões e atuação que não fosse tutelado pela profissão médica.

$\mathrm{Na}$ França, segundo Schultheiss (2001), os primeiros anos do século XX são marcados pela luta das enfermeiras pelo autoreconhecimento profissional. A ênfase no treinamento e no credenciamento culminou no estabelecimento de instituições voltadas para a formação dessa nova categoria, seguindo um modelo de profissionalização baseado na "feminização" da atenção ao paciente. A autora cita o exemplo de Louise Coutant, que dirigiu uma Associação de Enfermeiras ${ }^{6}$ e ficou conhecida pela luta em defesa dos direitos profissionais dessa categoria. Segundo Schultheiss, o Sindicato exigia de seus membros um diploma ou três anos de experiência comprovada. Louise Coutant se esforçou para ser conciliatória com os administradores hospitalares que não viam com bons olhos a força que o Sindicato vinha alcançando e no início do século XX já contava com cerca de 1.500 membros.

Ainda segundo a autora, a questão das relações de gênero no trabalho hospitalar foi sempre um tema polêmico na França. A visão que se tinha na época, entre os médicos, era de que uma

${ }^{5}$ Em virtude do próprio desenvolvimento das áreas de ginecologia e obstetrícia, lembra Rohden (2001). E, ainda, em virtude do desenvolvimento da saúde pública, de modo geral, como retrata George Rosen (1976).

${ }^{6}$ Esta Associação se propunha servir como uma agencia central de empregos e defender os direitos $e$ interesses de seus membros nas disputas que por ventura viessem a surgir nas suas funções. 
Educadoras Sanitárias e Enfermeiras

mulher solteira não podia ser um ator social responsável fora do contexto religioso. (Schultheiss, 2001:125)

$\mathrm{Na}$ América Latina, a crescente urbanização, o aparelhamento do Estado, as ideologias de modernização e de construção nacional e o surgimento das grandes epidemias como a febre amarela, a malária, a tuberculose e a ancilostomíase - criaram novas possibilidades para as educadoras sanitárias e, mais tarde, para as enfermeiras de saúde pública e, nesse mesmo compasso, para o trabalho feminino. No cenário brasileiro, a partir do final dos anos de 1920, a visitadora sanitária foi adquirindo prestígio profissional, cada vez mais reconhecida como um ator importante dos serviços de saúde pública. Seu espaço diante da autoridade médica, ainda que reduzido, tinha status legítimo. Isto se devia, em parte, por ter conseguido reivindicar algum monopólio sobre uma área do conhecimento - a "educação sanitária" -, particularmente por sua atuação nos centros de saúde, postos de higiene e atividades de visitação. Falar sobre a formação de recursos humanos nesse período exige colocar em destaque a expansão do papel da mulher na sociedade brasileira em especial da visitadora sanitária e da enfermeira de saúde pública.

Um exemplo pioneiro foi a Escola de Enfermeiras do Departamento Nacional de Saúde Pública (DNSP) - embrião da atual Escola Anna Nery - criada em 1921 por Carlos Chagas, uma das primeiras instituições a valorizar o trabalho feminino. Carlos Chagas afirmava, nessa época: "sem nenhum exagero asseguramos que não se poderá mais admitir uma administração sanitária moderna, à qual falte esse órgão valioso de ação, representado pela enfermeira visitadora".7

Não foi apenas a Escola Anna Nery que possibilitou à enfermagem de saúde pública projetar-se como área de conhecimento e atividade profissional valorizada. Em São Paulo,

7 O Jornal, Rio de Janeiro, sete de abril de 1922. Ver também Biblioteca Virtual Carlos Chagas www.prossiga.br/Chagas. Acesso em 01 de junho de 2006. 
o fruto desse esforço inicial veio com a criação, em 1925, do Curso de Educação Sanitária, ministrado no Centro de Saúde Modelo do Instituto de Higiene de São Paulo. ${ }^{8} \mathrm{O}$ projeto dos centros de saúde possibilitava maior proximidade com a população carente das cidades e do campo, grande parte afetada por endemias. A ancilostomíase, a malária e a febre amarela atacavam com maior violência as populações pobres daquelas regiões. A necessidade premente de enfermeiras para trabalhar nas campanhas sanitárias $e$ a longa duração do curso de enfermagem conduziram à criação do Curso de Educação Sanitária, com requisitos menos exigentes de formação. Esse curso teria duração de um ano e seis meses $e$ ofereceria experiência teórica e prática às visitadoras. Aos poucos, as visitadoras de higiene foram sendo substituídas por enfermeiras graduadas pela Escola de Enfermagem da Universidade de São Paulo, a partir da segunda metade dos anos de 1940.

Mas, era indiscutível a importância das visitadoras de saúde pública. Os centros de saúde e postos de higiene dispunham de número igual de médicos e visitadoras e a falta de visitadoras em um centro ou posto já os caracterizava como "subposto". O centro de saúde permitia às visitadoras sanitárias exercer determinadas atividades relativamente independentes da supervisão $e$ orientação dos médicos.

Nos serviços de higiene infantil a presença feminina era marcante. As visitadoras e, mais tarde, as enfermeiras de saúde pública, ficavam encarregadas de levar às mães todos os preceitos necessários à criação de seus filhos. Ficavam encarregadas ainda de verificar quaisquer condições patológicas ou anomalias orgânicas existentes nas crianças, e finalmente responsabilizava-se por todas as providências relativas aos problemas de higiene em um distrito sanitário. Quanto à sua atuação nos serviços de combate à tuberculose encontra-se ali, ainda segundo Carlos

8 Para um estudo mais aprofundado sobre a trajetória histórica do Instituto de Higiene de São Paulo ver: Candeias, 1984; Vasconcellos, 1995; Faria, 1999; 2001; 2003 e Campos, 2002. 
Educadoras Sanitárias e Enfermeiras

Chagas, um "exemplo valioso de atividade das enfermeiras visitadoras. Aí, mais do que em qualquer outro ramo da administração sanitária, sua função é preponderante $e$ imprescindível". (ver nota 7) E, ainda,

na luta contra a tuberculose melhor se experimenta e mais eficazmente se exercita a atividade da enfermeira visitadora. O combate ao contagio, (...) constitui a base primordial da luta contra a doença; e nessa orientação, (...) cabe à palavra carinhosa e persuasiva da enfermeira visitadora, cabe à força de sua inteligência a ao poder soberano de seu coração, realizar a obra abençoada (...). (cf. Chagas, 1922:110)

Estava ali o embrião da atuação ainda mais destacada da enfermagem de saúde pública na Campanha Nacional contra a Tuberculose, em todo o país, a partir da década de 1940.

Tanto nos serviços da Tuberculose, quanto nos serviços de higiene rural cabia à visitadora sanitária introduzir "hábitos $e$ costumes de civilização", tarefa considerada imprescindível. Em artigo publicado na Revista Anais de Enfermagem, Evandro Chagas - irmão de Carlos Chagas - chama a atenção para o papel decisivo dessa profissional na assistência médica e na educação sanitária. Embora reconhecesse que seria mais fácil a atuação masculina nas áreas interioranas do país, em virtude das condições adversas à mulher, acreditava que somente ela seria capaz de "vencer as tradições e os preconceitos das populações rurais, mais habituadas a verem na obra pública a ação perseguidora do que a atividade protetora e benfazeja". (cf. E. Chagas, 1938:5-7)

Pioneiras no campo da Educação Sanitária e da Enfermagem em Saúde Pública, como Maria Antonietta de Castro, Ruth Sandoval Marcondes e Edith de Magalhães Fraenkel, devem ser lembradas como exemplos de dedicação e luta pela conquista de um espaço feminino no campo da saúde. Maria Antonietta de Castro foi uma das primeiras Educadoras Sanitárias 
do país e fez parte do Primeiro Curso de Educadoras Sanitárias do Instituto de Higiene de São Paulo; Ruth Sandoval Marcondes foi responsável pela organização do Primeiro Curso de Educação em Saúde Pública da Faculdade de Saúde Pública da USP e Edith de Magalhães Fraenkel, que se diplomou na Escola de Enfermagem do Philadelphia General Hospital, em 1925, foi convidada pela Fundação Rockefeller para organizar e dirigir a Escola de Enfermagem da Universidade de São Paulo, criada em 1942.

A Fundação Rockefeller ${ }^{9}$ desempenhou um papel importante no processo de valorização e na própria criação do "mundo da enfermagem de saúde pública" no Brasil. Nesse sentido, este artigo discute a contribuição da Rockefeller para o desenvolvimento do campo que surgia como a "ciência sanitária", tanto em São Paulo como de modo geral em todo o país. A Rockefeller apoiou, com recursos humanos e financeiros, a criação de serviços de enfermagem, valorizando, particularmente, o trabalho de saúde pública. Apoiou, ainda, com base em um modelo pedagógico desenvolvido pelas lideranças da enfermagem norte-americana, a criação do ensino profissional da enfermeira de saúde pública, para que pudesse atuar nos serviços de administração sanitária, assim como em qualquer atividade relacionada à sua profissão. Havia uma preocupação em não formar "profissionais menores", e por tal razão o treinamento de saúde pública não excluía o embasamento no trabalho hospitalar.

O modelo americano dos health centers e a formação de visitadoras sanitárias e enfermeiras em saúde pública

O contato com cientistas e instituições norte-americanos marcou uma nova fase para o campo da saúde pública no Brasil. Ao aqui chegar, em 1916, a Fundação Rockefeller concedeu várias bolsas de estudos para o curso de Saúde Pública da School of

9 Para um estudo mais aprofundado sobre a atuação da Fundação Rockefeller no Brasil e em outros países ver: Collier, 1976; Howe, 1982; Cueto, 1994; Marinho, 2001; Faria, 2003; Castro Santos e Faria, 2003. 
Educadoras Sanitárias e Enfermeiras

Hygiene and Public Health, da Johns Hopkins University, em Baltimore, nos Estados Unidos. (Faria, 2003) ${ }^{10}$ Os padrões e métodos de trabalho dos norte-americanos começaram a influenciar uma nova geração de cientistas brasileiros. Esse grupo trouxe para o Brasil uma concepção renovadora de saúde pública baseada na educação sanitária e na formação de profissionais na área da saúde pública. Tratava-se de uma proposta de intervenção sanitária representada pelos centros de saúde (health centers) e postos de higiene (county health units). O modelo dos health centers concebia às visitadoras sanitárias e às enfermeiras de saúde pública um papel de destaque nos programas e serviços sanitários e teve no grupo paulista formado por sanitaristas do porte de Geraldo Horácio de Paula Souza ${ }^{11}$ e Francisco Borges Vieira e no grupo carioca liderado por de João de Barros Barreto e José P. Fontenelle seus principais incentivadores e defensores.

O Brasil adotou o modelo americano dos health centers, divulgado pela Fundação Rockefeller baseado na assistência educativa materno-infantil, no atendimento de tuberculosos, na educação sanitária, na higiene pré-natal, infantil e rural, em análises laboratoriais e na formação de profissionais de saúde pública. Mas há diferenças marcantes quanto à origem,

\footnotetext{
${ }^{10}$ Ver, ainda, The Rockefeller Directory of Fellowship Awards. "Roster of Fellows and Scholars, 1917-1950", RAC, 1950.

${ }^{11}$ Geraldo Horácio de Paula Souza (1889-1951) foi diretor do Instituto de Higiene de São Paulo no período entre 1922 e 1951 e diretor do Serviço Sanitário entre 1922 e 1927. Durante sua gestão no Serviço Sanitário promoveu a reforma dos serviços de saúde do estado, "Reforma Paula Souza". A Reforma resultou no surgimento dos health centers, difundidos pela Fundação Rockefeller. Os centros de saúde tinham como objetivo primordial a formação de visitadoras sanitárias e enfermeiras de saúde pública. Paula Souza foi um dos principais interlocutores da Fundação Rockefeller na adoção do modelo norte-americano de saúde pública e na organização de um novo campo de atuação para as visitadoras e enfermeiras de saúde pública. Ver Faria, 2002.
} 
concepção, organização, e, em especial, quanto ao tipo de incentivo recebido para montagem deste serviço de saúde. ${ }^{12}$

Nesta fase, instaura-se no país uma nova concepção "campanhista", cujo elemento renovador estava na ênfase na saúde como um processo pedagógico. Nessa proposta, a educação sanitária era o elemento-chave para a formação de uma consciência sanitária da população. (Castro Santos e Faria, 2005) O novo modelo de saúde desencadeou um movimento de reconfiguração do campo médico, que buscou instaurar novas práticas e concepções - promoção da saúde e prevenção das doenças -, ao mesmo tempo em que passou a exigir o concurso de novos agentes - os profissionais de saúde pública. A formação desses profissionais e a difusão da educação sanitária tornaram-se, pois, imperativos.

As novas agentes da saúde pública: "as mensageiras de higiene"

O auxílio pedagógico, financeiro e humano da Fundação Rockefeller para a montagem do ensino federal de enfermagem marcou uma nova fase no desenvolvimento médico e hospitalar $e$ de saúde pública no país. A política de concessão de bolsas de estudos logo se ampliou para a área de enfermagem de saúde pública, considerada uma pedra-de-toque da educação sanitária nos países assistidos pela Fundação. Daí resultou o auxílio para a criação, em 1923, da Escola de Enfermagem Anna Nery, no Rio de Janeiro - que se tornou uma instituição-modelo para todo o país, operando em sintonia com a Faculdade de Medicina da

\footnotetext{
${ }^{12}$ Ver Castro Santos e Faria, 2002. Aqui discutimos o movimento que deu origem aos centros de saúde no Brasil, a posição de prestígio que desfrutaram os sanitaristas e a enfermagem de saúde pública e o papel desempenhado pela Fundação Rockefeller neste processo. Traçamos, ainda, um quadro comparativo entre a experiência paulista e o health center movement, nos estados norteamericanos de Wisconsin e Ohio, chamando a atenção para os programas e as medidas sanitárias implementadas nessas regiões.
} 


\section{Educadoras Sanitárias e Enfermeiras}

Capital e com os serviços sanitários do Departamento Nacional de Saúde Pública. ${ }^{13}$

Como apontamos anteriormente, em São Paulo, o fruto desse esforço inicial veio com a criação, em 1925, do Curso de Educação Sanitária ${ }^{14}$, destinado a transformar professoras primárias em agentes comunitárias. ${ }^{15} \mathrm{O}$ objetivo era divulgar entre a população carente noções e conceitos de higiene, formando a consciência sanitária da população. "Como organismos de difusão de conhecimentos sanitários, avulta a obra das visitadoras de higiene ou educadoras sanitárias, emanações do centro de saúde". (Souza e Borges Vieira, 1944)

O Curso de Educadoras Sanitárias foi organizado no Centro de Saúde Modelo do Instituto de Higiene de São Paulo - o primeiro centro de saúde do país. No seu primeiro ano de funcionamento, o Centro de Saúde teve cerca de 22 mil inscritos. ${ }^{16}$

\footnotetext{
${ }^{13}$ Sobre os primeiros tempos da Escola de Enfermagem Anna Nery ver os trabalhos de Barreira e Franco Santos, 1992; 1999.

${ }^{14}$ Decreto $\mathrm{n}^{\circ} 4.089$, de 17 de agosto de 1926. Coleção de Leis e Decretos do Estado de São Paulo, 1925, p. 155-9. O Curso foi criado durante a reforma organizacional de 1925 ou "Reforma Paula Souza". A reforma foi efetivada por meio do Decreto 3.876, de 11 de julho de 1925. Ocorreu durante o governo de Carlos de Campos e foi importante na reformulação do conjunto dos serviços públicos de saúde paulistas. Para um estudo mais aprofundado sobre este tema ver Faria, 2002.

${ }^{15}$ De acordo com os dados colhidos por Rocha - nas fichas de histórico escolar dos alunos matriculados no Curso de Educadoras Sanitárias, entre os anos de 1925 e 1930 - de 130 alunos matriculados, 82,3\% eram mulheres e 17,7\% homens e, ainda, 112 exerciam o magistério, o que equivale a um percentual de 86,1\%. Ver Rocha, 2003.

${ }^{16}$ Cerca de 14.691 para tratamento de verminoses e 2.347 para tratamento de sífilis e doenças venéreas. Nos serviços de higiene pré-natal e higiene infantil foram realizadas 1.564 consultas. No tocante às vacinações, cerca de 1.130 contra varíola e 1.900 contra febre tifóide. É expressivo também o número de exames de laboratório, no total de 16.000. Neste mesmo ano, o Centro de Saúde Modelo foi responsável pela distribuição de 14.712 impressos sobre noções de higiene e cuidados com a saúde. No Centro de Saúde do Brás foram matriculadas 4.112. "Centros de saúde". Folha da Manhã, 27 de novembro de 1925.
} 
As novas agentes da saúde pública - cujo recrutamento era feito entre professoras primárias - atuavam junto aos centros de saúde elaborando cartazes de propaganda, realizando visitas domiciliares, fornecendo conselhos de "puericultura", fazendo palestras, exposições, conferências. As educadoras sanitárias distritais; escolares de higiene; de higiene infantil; de higiene de centros de saúde, de postos, dispensários e hospitais; de higiene para o serviço especial de sífilis e doenças venéreas - percorriam escolas, cortiços e fábricas divulgando entre a população carente, noções e conceitos de higiene. (Cortez, 1926:25-28)

No conjunto das iniciativas de formação do novo campo, as professoras primárias foram vistas como importantes aliadas na obra de divulgação das noções de higiene. Nas justificativas para a escolha das normalistas, é recorrente a afirmação de ter sido essa solução engendrada em função da falta de enfermeiras formadas. As professoras atuaram como visitadoras sanitárias dos serviços de saúde estaduais até serem substituídas, gradativamente, por profissionais com formação e treinamento em saúde pública. $\mathrm{A}$ primeira turma contou com dezesseis moças. ${ }^{17} \mathrm{~A}$ justificativa para a opção pelas professoras primárias pos em destaque a importância da formação pedagógica.

A ausência de uma escola de enfermagem eficiente em São Paulo, em 1925, fez com que se buscasse sanar essa falta aproveitando professores diplomados que, após um curso de especialização sanitária (no Instituto de Higiene) pudessem ser encarregados de serviços de assistência social, serviços que em outros lugares são feitos pelas enfermeiras visitadoras de saúde publica. $\mathrm{O}$ resultado foi tão bom que mesmo que se venha a fundar uma escola de enfermagem, as suas diplomadas poucas vezes poderão ser tão eficientes como as atuais educadoras já imbuídas da

${ }^{17}$ Carta de Paula Souza a F. F. Russell, 02 de janeiro de 1925. Centro de Memória da Faculdade de Saúde Pública de São Paulo. 
Educadoras Sanitárias e Enfermeiras

noção educativa, antes que da medica. (Souza e Borges Vieira, 1936:34-5; Rocha, 2003:155)

Após um ano e meio de curso, as professoras primárias voltariam às suas escolas e seriam "elemento-chave no processo de educação sanitária da coletividade paulista, tendo como ponto de partida a ação sobre os escolares". (Mascarenhas e Freitas, 1959) Artigos publicados no jornal Folha da Manhã, neste período, chamavam a atenção para a estreita ligação entre esse novo campo que se abria e a carreira do magistério:

As professoras sob o título de educadoras de higiene, após um curso especial, aconselham o povo à prática dos preceitos higiênicos ${ }^{18}$. É interessante observar-se as educadoras, em seus aventais brancos, a ministrar com especial desvelo salutares conselhos à multidão que recorre aos centros de saúde, onde a par de orientações higiênicas que recebe, é carinhosamente medicada. ${ }^{19}$

Em relatório sobre os serviços prestados durante o ano de 1925 pelo Serviço Sanitário Paulista, Paula Souza chama a atenção para a importância do centro de saúde como um "verdadeiro órgão de sondagem social" - que visa, sobretudo, a família - e do papel decisivo da educadora sanitária. De acordo com o relatório, o papel da educadora é, através de suas visitas, encaminhar os necessitados para os centros de cuidados médicos e transmitir noções de puericultura para as mães. Nesta fase, as taxas de mortalidade infantil eram elevadas em São Paulo. De acordo com as estatísticas da época, cerca de $49 \%$ dos óbitos infantis eram causados por doenças do aparelho digestivo, seguindo-se com $18 \%$ as causas pré-natais e neonatais e, com $7 \%$ de mortes, as doenças endêmicas e infecciosas. Para Paula Souza,

${ }^{18}$ Inspetoria de Educação Sanitária e Centros de Saúde. O que representa para o público esse novo serviço oficial. Folha da Manhã, 17 de novembro de 1925.

${ }^{19}$ Os centros de saúde. Folha da Manhã, 14 de novembro de 1925. 
"a absoluta carência de noções de puericultura por parte da grande maioria das mães" era um dos elementos principais da mortalidade infantil. ${ }^{20}$

O Curso de Educadoras Sanitárias consubstanciou-se numa das expressões da nova política de saúde pública, que entendia que os problemas de higiene eram resultado da falta de educação sanitária. Nesse sentido, a possibilidade de eliminação dos graves problemas de saúde se daria através da ação educativa das "mensageiras da saúde". Duas décadas depois do Primeiro Curso de Educadoras Sanitárias, a importância da atuação dessas profissionais era relatada em artigo publicado em importante revista sobre higiene e saúde pública da época:

Não se pode negar que tais auxiliares têm prestado os mais assinalados serviços à causa da saúde pública paulista, a tal ponto que hoje são disputadas, tanto pelos serviços oficiais como por organizações particulares médico-assistenciais, constituindo classe que assim tende a perdurar. (Souza e Borges Vieira, 1948:35)

A seguir apresentamos um quadro geral do Curso de Educação Sanitária, o modo como foi concebido e estruturado, tendo nas entrevistas concedidas pelas Educadoras Sanitárias Marília Belluomini e Ruth Sandoval Marcondes duas importantes contribuições para nossa discussão. Marília Belluomini fez o Curso de Educadora Sanitária na Faculdade de Saúde Pública da USP, em 1957 e trabalhou com Raphael de Paula Souza ${ }^{21}$ no Instituto de Saúde e Serviço Social da FSP. ${ }^{22}$ Ruth Sandoval Marcondes foi

\footnotetext{
${ }^{20}$ Serviço Sanitário do Estado de São Paulo, maio de 1926. Arquivo FSP/USP. Caixa "Coleção Paula Souza". Originais de trabalhos não publicados.

${ }^{21}$ Tisiologista, formado pela Faculdade de Medicina do Rio de Janeiro, em 1923, foi professor catedrático de tisiologia da Faculdade de Saúde Pública da USP e figura destacada na Campanha Nacional contra a Tuberculose, desde a década de 1940.

${ }^{22}$ Entrevista realizada na Faculdade de Saúde Pública da USP no dia 22 de junho de 2004
} 
Educadoras Sanitárias e Enfermeiras

Professora Catedrática de Educação Sanitária da Faculdade de Saúde Pública e responsável pela organização do Primeiro Curso de Educação em Saúde Pública da Faculdade. ${ }^{23}$ Antes da discussão do material empírico, situamos o contexto mais amplo da produção dos discursos de modernização no Brasil, em que se constituíram o tema $e$ as políticas de educação sanitária.

\section{"A educação sanitária semeia, a raça colherá o fruto"}

Um vago "biologismo" e sua versão de "apologia da eugenia" eram parte da retórica de modernização da época. A "regeneração física, intelectual e moral" dos indivíduos ${ }^{24}$ era termos correntes nas elites nacionais. A questão da "modernização conservadora" no Brasil dos primeiros decênios da República, em relação à preocupação das elites com a construção nacional e a geração de raças fortes, foi discutida recentemente por Fabíola Rohden. Do ponto de vista da "higiene da raça", tornava-se fundamental a geração de "proles saudáveis". A autora analisa os embates entre médicos, intelectuais e políticos, em torno de questões como reprodução e sexualidade, durante as primeiras décadas do século XX. No plano dos discursos, Rohden indica que esses temas caminhavam passo a passo com a conformação de projetos de intervenção e expressavam os interesses públicos por essas dimensões. (Rohden, 2003:14) Segundo Rohden, o controle sobre a capacidade reprodutiva foi a base em torno da qual se construíram as prerrogativas sobre as capacidades $e$ funções sociais de cada gênero. Nesse projeto de construção da nação, a educação das mães, "sacerdotisas da eugenia", era fundamental, pois envolvia de maneira mais profunda a relação entre mulher $e$ raça. Nesse sentido, era preciso cuidar da educação física, mental $e$ espiritual da mulher, pois era quem transmitiria à prole as

${ }^{23}$ Entrevista realizada na Faculdade de Saúde Pública da USP no dia 27 de julho de 2004.

${ }^{24}$ Ver, por exemplo, os discursos do educador Oscar Thompson, citados em Rocha, 2003:160-163. Ver também Castro Santos e Faria, 2005. 
qualidades necessárias para a formação de raças fortes $e$ saudáveis. A autora analisa, ainda, algumas teses de médicos formados pela Faculdade de Medicina do Rio de Janeiro, que mostravam a necessidade de educar a mulher "conscientemente e cientificamente", pois a causa da fraqueza de seu sexo (atrofia de órgãos, de sistemas e do cérebro) estava justamente na inadequada educação higiênica recebida até então. As preocupações com a "equivalência" entre os sexos visavam mais o progresso da nação do que os direitos das mulheres. Educar a mulher, portanto, era garantir a geração de rebentos saudáveis e a compreensão de sua missão procriadora. Não havia, segundo Rohden, preocupação em educar mulheres para atuarem profissionalmente, conscientes de seus direitos e deveres na sociedade. A ênfase na educação era para a maternidade. $\mathrm{O}$ futuro da nação e o progresso do país dependiam de que a mulher cumprisse "o seu papel da melhor forma possível, de acordo com as orientações da medicina". (Id.:202)

O trabalho de Rohden não dedica especial atenção às visitadoras e enfermeiras - um elo importante nesse projeto de saúde pública e eugenismo -, talvez por essa razão, deixa de contemplar a possibilidade de que, apesar do reducionismo biológico, a preocupação com a educação cívica pudesse superar as balizas da eugenia, um dos legados da criação dos centros de saúde, de tal sorte que o papel social das novas profissionais não se resumia, apenas, ao de "sacerdotisas da eugenia". Nas consultas e nos trabalhos de visitação realizados pelas educadoras sanitárias e pelas enfermeiras no Centro de Saúde Modelo havia também uma preocupação com a educação e formação cívica dos indivíduos.

Saúde, instrução cívica e moral foi o tripé sobre o qual se sustentou a atuação das novas "mensageiras da saúde", incumbidas de ensinar a população brasileira o "evangelho da higiene". Assim, as educadoras e enfermeiras estariam cumprindo a missão para a qual foram convocadas: educação e formação 


\section{Educadoras Sanitárias e Enfermeiras}

cívica dos indivíduos. ${ }^{25} \mathrm{O}$ aprendizado se fazia, quer no Centro de Saúde Modelo do Instituto de Higiene, quer no estágio junto à Inspetoria de Educação Sanitária e Centros de Saúde. Dispondo sobre os objetivos e o conteúdo do curso e sobre os critérios de seleção e avaliação, o Regulamento do Curso de Educadoras Sanitárias ${ }^{26}$ postulava a formação de novas agentes de saúde, cuja atuação deveria possibilitar a disseminação de hábitos de higiene.

A admissão ao curso se fazia mediante a aprovação em exame sobre cultura geral, noções de anatomia e de fisiologia humanas. Como requisito para a inscrição, a candidata deveria apresentar à direção do Instituto de Higiene um requerimento acompanhado de documentos que comprovassem ${ }^{27}$ : ser diplomada em escola normal do Estado; professora efetiva em Grupo Escolar, com mais de seis meses de magistério; ter idade superior a 18 e inferior a 30 anos e aptidão para o cargo comprovada por exame médico. ${ }^{28}$

O curso cobria um período de um ano e seis meses $e$ enfatizava $\mathrm{o}$ trabalho em saúde pública. O programa era composto de nove matérias divididas em aulas teóricas - sobre a organização do serviço - e aulas práticas - sobre técnicas de vacinação $e$ atendimento à família, além de visitas domiciliares. Os últimos seis meses eram dedicados às atividades práticas em estágios nos serviços sanitários estaduais. A professora Azalia Machado - única mulher do quadro de docentes do Curso estava entre os onze professores que ministraram disciplinas para

\footnotetext{
${ }^{25}$ Ver discurso de Maria Antonieta de Castro, na cerimônia de entrega de diplomas à primeira turma de educadoras sanitárias. Correio Paulistano, 9 de dezembro de 1927. Ver também, Candeias, 1984 e Rocha, 2003.

${ }^{26}$ Decreto ${ }^{\circ} 4.089$, de 17 de agosto de 1926. Coleção das Leis e Decretos do Estado de São Paulo de 1925:155-9.

${ }^{27}$ Edital - Instituto de Higiene de São Paulo. Correio Paulistano, de 5 de janeiro de 1928.

${ }^{28}$ Decreto $n^{\circ} 4.089$, de 17 de agosto de 1926. Coleção das Leis e Decretos do Estado de São Paulo de 1925:155-9. Ver também Candeias, 1984.
} 
a turma de $1925 .^{29}$ A partir do início dos anos 40, a docência feminina tornou-se cada mais acentuada, com se verá mais adiante. $^{30}$

A primeira turma de educadoras sanitárias formou-se em 1927. A Visitadora Sanitária Maria Antonietta de Castro ${ }^{31}$, pioneira no campo da Educação Sanitária em São Paulo e responsável pela organização de inúmeras campanhas de educação sanitária no estado, foi a oradora da turma.

E o nosso aprendizado se fez então, quer no curso de Higiene, sábia e proficientemente ministrado no Instituto de Higiene de São Paulo, quer no estágio junto à Inspetoria de Educação Sanitária e Centros de Saúde. E ao mesmo tempo em que estudávamos, íamos lançando a semente da educação sanitária. Basta dizer que, ingressadas em 7 de dezembro de 1924 para as novas fileiras, já em janeiro de

\footnotetext{
${ }^{29}$ Ministraram as disciplinas, para a turma de 1925, os seguintes professores: Alberto Santiago, Almeida Junior, Nuno Guerner, Garcia Braga, Dalmacio Azevedo, Samuel Pessoa, Paulo Saes, Paulo Aguiar, José Maria Gomes, Clovis Corrêa, Azalia Machado. Ver Candeias, 1984.

${ }^{30}$ As matérias que compunham o currículo eram: noções de Bacteriologia aplicadas à Higiene; noções de Parasitologia e Entomologia; noções de Estatística Vital e de Epidemiologia; Higiene Pessoal, Nutrição e Dietética; Higiene Infantil; Higiene Mental, Social e do Trabalho; Higiene Urbana, Rural e das Habitações; Ética; Educação e Administração Sanitárias; Princípios e Processos de Enfermagem em Saúde Publica. Decreto 4.089, de 17 de agosto de 1926. Coleção das Leis e Decretos do Estado de São Paulo. Ver também Candeias, 1988:347-365.

${ }^{31}$ Maria Antonietta de Castro (1892-1984), da primeira turma de educadores sanitários do Instituto de Higiene, foi designada, em 1927, para o cargo de Educador Sanitário Chefe, responsabilizando-se pela instalação, organização e direção das primeiras atividades nos centros de saúde e escolas paulistas. Neste mesmo ano, ganhou o Concurso Literário da Tarde da Criança, com o livro Papagaio Louro, livro de contos infantis para a divulgação da educação sanitária. Em 1929, foi homenageada pela Liga Brasileira de Higiene Mental, por um trabalho sobre o alcoolismo e, em 1950, pela Standard Oil Company of Brazil, como pioneira no campo da Educação Sanitária em São Paulo. Ver Rocha, 2003.
} 
Educadoras Sanitárias e Enfermeiras

1925 começávamos nossos trabalhos práticos. E, desde aí, foi um trabalhar sem tréguas. Temos consciência do nosso dever bem cumprido. É justo, pois, que hoje nos detenhamos, um pouco, na encosta da colina. Olhemos para traz. O terreno vem sendo preparado. A sementeira vem sendo feita. Aqui $e$ além, tufos de folhagem verde vêm aparecendo. A seara promete. E si o nosso próprio emblema o diz: "a educação sanitária semeia, a raça colherá os frutos", promissora será a colheita de amanhã (...) Colegas! Não nos detenhamos, porém, si os dias borrascosos parecem, felizmente, ter passado, é preciso seguir, subir mais e mais. Lá no alto, ver brilhar $e$ resplandecer o Sol da Saúde sobre a Raça Brasileira. ${ }^{32}$

Essa visão algo messiânica do papel da saúde como redentora da "raça brasileira" lembra a retórica inflamada dos higienistas da Liga Pró-Saneamento, como era o caso de Belisário Pena. O elemento novo estava na própria visão pragmática dos sanitaristas do Instituto de Higiene, atentos aos ditames da "saúde, instrução e moral". O curso das educadoras era um indicador dos novos rumos do papel da mulher na sociedade brasileira $e$, particularmente, em grandes centros como São Paulo.

Nos primeiros anos de operação, o Centro de Saúde Modelo contava com um grupo de agentes comunitárias divididas em "educadoras auxiliares", "educadoras monitoras" e "educadoras de campo". Em 1939, o novo regulamento ${ }^{33}$ do Curso de Educadoras Sanitárias habilitava as alunas diplomadas, independentemente de concurso, a exercerem cargos de agentes comunitárias, ou visitadora, nos serviços públicos do estado de São Paulo. (Mascarenhas, 1949) $)^{34}$

32 Correio Paulistano, 9 de dezembro de 1927. Ver Candeias, 1984.

${ }^{33}$ Pelo decreto 10.387, de 19 de julho, publicado na Secretaria de Estado da Educação e Saúde Pública, em 19 de julho de 1939.

${ }^{34}$ No ano seguinte foram ministradas na disciplina "Educação Sanitária" aulas sobre os seguintes temas: o que é educação sanitária; qual o papel da educadora diante dos vários problemas de saúde pública; quais os principais problemas de 
Lina Faria

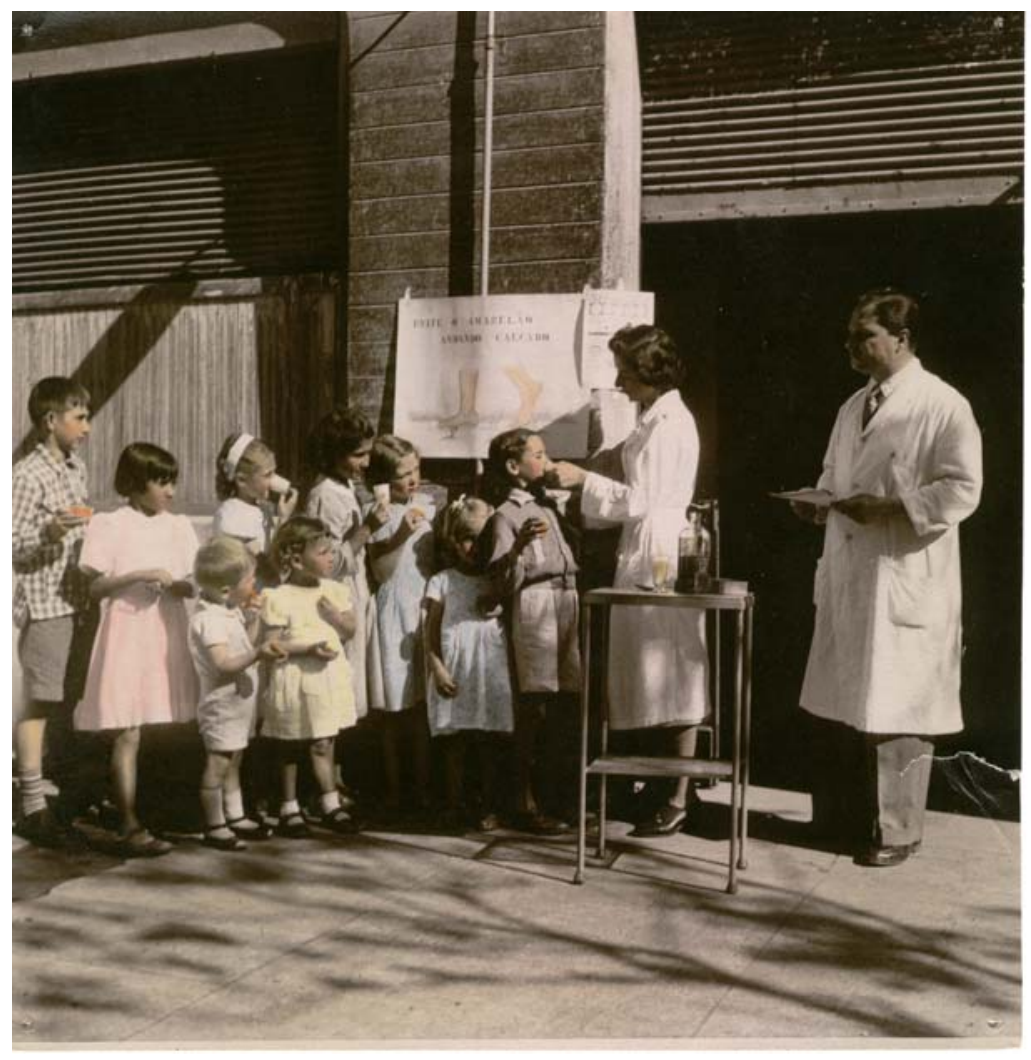

Se no primeiro ano do Curso de Educadoras Sanitárias havia somente uma professora no quadro docente ${ }^{35}$, no início dos anos 40, a docência feminina já era bastante significativa. Em 1941, a Educadora Sanitária Ismênia E. Carneiro ficou responsável pelas aulas da disciplina de Educação Sanitária. Os cursos de 1942 e 1943 de Educação Sanitária e de 1949 de

saúde pública; quais os cuidados que se deve ter com as gestantes, além de outros temas. Ver Mascarenhas e Freitas, 1959.

${ }^{35}$ Entrevista realizada na Faculdade de Saúde Pública da USP no dia 22 de junho de 2004. 
Educadoras Sanitárias e Enfermeiras

Psicologia Social ficaram sob a responsabilidade de Dina Salvatori, educadora sanitária formada em 1936. Em 1944 a disciplina de Educação Sanitária esteve a cargo de Zilda A. de Carvalho, formada em 1937. Em 1945, as aulas foram entregues a Lúcia Jardim, aluna da turma de 1936 do Curso de Educadoras Sanitárias e que acabava de regressar do Canadá, onde durante três anos freqüentou a Escola de Enfermagem de Toronto - criada com recursos da Fundação Rockefeller. Faziam parte, ainda, do quadro docente as professoras Adélia Vieira de Freitas, Alayde Chaves, Beatriz Marzagão, Dolly Mendes, Irany M. Krähenbühl, Ligia Silveira e Olentina Souza Lima. (Mascarenhas e Freitas, 1959)

Em 1949, pela primeira vez, uma educadora sanitária Adélia Vieira de Freitas - assumiu como função básica a supervisão geral do estágio das alunas do Curso de Educadoras Sanitárias. Pela primeira vez, também, foram ministradas aulas sobre Noções de Sociologia por Rodolfo dos Santos Mascarenhas. Neste mesmo ano, o sociólogo Oracy Nogueira - professor da Escola de Sociologia e Política de São Paulo - foi convidado para lecionar, juntamente com Dina Salvatori, a disciplina de Psicologia Social.

$\mathrm{Na}$ década de 50, a admissão ao curso de Educadoras Sanitárias ainda se fazia mediante a aprovação em exame que, segundo Marília Belluomini - aluna da turma de 1954 -, contava com prova de redação, português, matemática e química. O Curso tinha duração de um ano, com dedicação integral e quinze dias de férias. As educadoras assistiam a aulas de psicologia, química orgânica, epidemiologia e ciências sociais e, ao final do Curso, realizavam estágios nos centros de saúde ou em outros serviços estaduais de saúde. Nas palavras de Belluomini,

- Curso de Educadoras Sanitárias conferiu prestígio às educadoras. (...) Foi, sem dúvida, um dos melhores cursos na área de saúde pública. Nós trabalhávamos diretamente com o público, orientando e educando. Nas aulas de epidemiologia tínhamos noção de todas as doenças, 
principalmente aquelas mais freqüentes em crianças. A duração do curso era de um ano, em tempo integral. Ao final, realizávamos uma série de estágios em outros serviços ou aqui mesmo no Centro de Saúde. (...) No atendimento ambulatorial do Centro de Saúde dávamos atendimentos aos doentes de tuberculose e lepra e, ainda, conselhos sobre higiene às famílias [dos doentes].

Marília Belluomini reafirma o papel das educadoras sanitárias na conquista de um espaço de atuação e legitimidade. A "noção educativa", e não apenas "médica", constituía a base de suas identidades profissionais.

\section{O Serviço de Enfermagem: em direção ao reconhecimento profissional}

Em 1942, foi criado um programa cooperativo de saúde pública entre os governos do Brasil e dos Estados Unidos para auxílio ao Serviço de Enfermagem do Instituto de Higiene de São Paulo. O apoio ao Serviço de Enfermagem partiu da agência norte-americana - Instituto de Assuntos Interamericanos (IIAA). (Castro Santos e Faria, 2005) A Rockefeller, que havia apoiado fortemente o Curso de Educadoras, contribuiu de modo subsidiário para o empreendimento, concedendo bolsas para estágio nos Estados Unidos e Canadá e financiando a aquisição de livros científicos e a montagem de laboratório.

A criação do Serviço de Enfermagem foi um passo importante na conquista do reconhecimento profissional da enfermagem de saúde pública. A partir deste momento, a enfermeira começa a conquistar algum capital cultural $e$ poder social entre seus pares-competidores, porque foi capaz de impor um modelo de ação profissional - uma proposta de ação sanitária calcada na educação e na formação cívica dos indivíduos. Segundo Candeias (1988), dois motivos fundamentaram esta iniciativa: o reconhecimento internacional da importância da educação em saúde na prática da saúde pública e a inexistência de enfermeiras na rede de serviços federais. 
Educadoras Sanitárias e Enfermeiras

O regulamento ${ }^{36}$ para estágio no Serviço de Enfermagem em Saúde Pública do Instituto de Higiene - 16 semanas de 40 horas, incluindo aulas práticas e teóricas - aconselhava que as alunas tivessem cursado a Escola de Enfermagem da Universidade de São $\mathrm{Paulo}^{37}$, na época, dirigida por Edith de Magalhães Fraenkel. A Escola ficava encarregada de fornecer todo o material necessário ao estágio das enfermeiras. O Centro de Saúde Modelo funcionava como um campo de treinamento para as alunas das Escolas de Enfermagem da Faculdade de Medicina e da Cruz Vermelha Brasileira, filial de São Paulo. Recebia, ainda, alunas de outras escolas do Brasil e enfermeiras diplomadas de outros países da América Latina.

Se, na teoria (ao menos segundo as autoridades sanitárias), a relação entre a educação sanitária $e$ a enfermagem deveria ser de complementaridade, na prática, envolvia tensões e problemas de hierarquia e autonomia. A Educadora Sanitária Ruth Sandoval Marcondes, em entrevista que nos foi concedida, indica que em determinado momento houve uma sobreposição funcional das duas categorias emergentes; a Educadora Sanitária (1925) e a Enfermeira de Saúde Pública (1942). Essa sobreposição deu origem a "ciúmes" e conflitos entre as profissionais. Os momentos

${ }^{36}$ Interim Report May 12, 1947 to February 25, 1950. Regulamento para estágio no Serviço de Enfermagem de Saúde Pública da Faculdade de Higiene e Saúde Pública. Fundo SESP/ Fiocruz, Departamento de Arquivo e Documentação/Casa de Oswaldo Cruz.

${ }^{37}$ A Escola de Enfermagem da Universidade de São Paulo foi criada, também em 1942, pelo decreto n. 13.040 de 31 de outubro, em um programa de cooperação entre o governo do Estado de São Paulo, o SESP e o governo dos Estados Unidos. O programa da Escola de Enfermagem abrangia um período de três anos, dividido em Pré-clínico, Júnior, Intermediário e Sênior. Quatro meses do período Sênior eram reservados para estágio no Serviço de Enfermagem do Instituto de Higiene. Ver "Completion agreement NT-SPA-14. Escola de Enfermagem de São Paulo. Universidade de São Paulo, Faculdade de Medicina, 1942". Fundo SESP, Departamento de Arquivo e Documentação. Casa de Oswaldo Cruz, Fiocruz. Para um estudo mais aprofundado sobre a criação do Serviço de Enfermagem do Instituto de Higiene e da Escola de Enfermagem da Faculdade de Medicina da USP, ver Castro Santos e Faria, 2005. 
difíceis para o Curso de Educadoras Sanitárias, a partir da implantação da Escola de Enfermagem na Universidade de São Paulo, em outubro de 1942, fizeram vir à tona questões de hierarquia profissional e competência técnica. Com o passar dos anos, a liderança profissional das enfermeiras diplomadas tornouse incontestável. ${ }^{38}$

O principal objetivo do Serviço de Enfermagem era

preparar pessoal e desenvolver recursos para instrução de enfermagem de saúde pública em nível pós-básico, incluindo a prática supervisionada em serviços de saúde pública urbanos e rurais. ${ }^{39}$

As educadoras e enfermeiras recebiam aulas de técnica de higiene pré-natal, bacteriologia, parasitologia, química, fisiologia aplicada à higiene, higiene industrial, bioestatística, epidemiologia, higiene rural, higiene pessoal, higiene infantil, higiene pré-natal, higiene mental e higiene dental.

No início da década de 50, havia cerca de 150 enfermeiras graduadas no Estado de São Paulo. Ao se formarem, as enfermeiras eram contratadas por instituições dentro $e$ fora do estado: em primeiro lugar, a própria Faculdade de Higiene e Saúde Pública e o Hospital das Clínicas, onde recebia seu treinamento profissional. Além dessas instituições, o Centro de

\footnotetext{
38 Segundo Ruth Sandoval Marcondes, o Curso de Educadora Sanitária durou até 1961. Entre os anos de criação do curso e a década de 1960, o Instituto de Higiene diplomou 466 educadoras sanitárias. Em 1967 foi organizado na Faculdade de Saúde Pública o primeiro Curso de Educação em Saúde Pública. Entrevista realizada na Faculdade de Saúde Pública da USP no dia 27 de julho de 2004. Sugere-se a leitura do artigo de Mascarenhas, R. S, Teixeira, M. S. e Marcondes, R. S., (1962) "Funções do pessoal de enfermagem e educação sanitária nos serviços de saúde pública". Arquivos de Higiene e Saúde Pública. São Paulo: 27 (93) e o texto importante de Candeias, 1988.

${ }^{39}$ Curso de Enfermagem de Saúde Pública da Escola de Saúde Pública da Universidade de São Paulo, 07/10/1951. Fundo SESP/Fiocruz, Departamento de Arquivo e Documentação/Casa de Oswaldo Cruz.
} 
Educadoras Sanitárias e Enfermeiras

Saúde de Araraquara, o Serviço Especial de Saúde Pública, a Escola de Enfermagem de Porto Alegre, a Escola de Enfermagem da Bahia, a Escola de Enfermagem Rachel Haddock Lobo no Rio de Janeiro, o Hospital dos Servidores do Estado do Rio, a Legião Brasileira de Assistência de Pernambuco, o Serviço Nacional de Tuberculose do Rio Grande do Sul, o Departamento de Saúde de Santa Catarina, a Escola de Enfermagem de Recife. ${ }^{40}$

Nesse período, várias bolsas de estudos foram oferecidas pela Fundação Rockefeller e pelo SESP - Serviço Especial de Saúde Pública ${ }^{41}$-, para que as enfermeiras pudessem realizar estudos em enfermagem de saúde pública nos Estados Unidos. ${ }^{42}$ As Universidades de Boston, Minnesota, Toronto ${ }^{43}$ e Columbia foram as que mais receberam enfermeiras brasileiras nesta época. Essas universidades ofereciam excelentes cursos nas áreas de enfermagem de saúde pública, pediatria, ortopedia, psiquiatria, entre outros. A própria Fundação Rockefeller também concedeu bolsas de estudos para as enfermeiras formadas pela Escola de Enfermagem da Universidade de São Paulo ${ }^{44}$ e parte do material

${ }^{40}$ Completion agreement NT-SPA-14. Escola de Enfermagem de São Paulo. Universidade de São Paulo, Faculdade de Medicina, 1942. Fundo SESP/Fiocruz, Departamento de Arquivo e Documentação/Casa de Oswaldo Cruz.

${ }^{41}$ Criado em 1942, o Serviço Especial de Saúde Pública, resultado do convênio entre o Governo Federal e o Governo Roosevelt, nos Estados Unidos, realizou um programa de saúde e saneamento especialmente nas áreas mais pobres do interior do país. O SESP (além da Fundação Rockefeller) foi responsável pelo financiamento de bolsas de estudos para enfermeiras de saúde pública nos Estados Unidos e no Canadá. No período entre 1947 e 1951, o SESP concedeu cerca de 40 bolsas de estudos para enfermeiras graduadas pela Escola de Enfermagem da Faculdade de Medicina.

${ }^{42}$ Report of visit to Instituto de Higiene de São Paulo, 06/03/1945. Fundo SESP/ Casa de Oswaldo Cruz, Departamento de Arquivo e Documentação/Fiocruz.

${ }^{43}$ A Escola de Enfermagem em Toronto, Canadá, foi criada com recursos da Fundação Rockefeller, bem como o Teacher's College, na Universidade de Columbia, em Nova York.

${ }^{44}$ Biography Files. Arquivo contendo fichas biográficas de todos os bolsistas da Fundação Rockefeller, no período entre 1920 e 1950. Rockefeller Archive Center. 
Lina Faria

para instalação dos laboratórios da Escola de Enfermagem, além de doações para bibliotecas.

\section{A formação de uma identidade profissional}

A autonomia do campo é condição para a atividade científica, inclusive para a ciência aplicada. O problema da divisão do trabalho profissional envolve autoridade do saber, monopólio sobre uma área do conhecimento e poder. Esses fatores hierarquizam as ocupações. Para Freidson (1975, 1998), a autonomia é vista como um atributo relevante para o poder de uma profissão, porque essa autonomia marca o prestígio, o status, dos profissionais. A questão de gênero não foi, a rigor, enfrentada pelo autor, e talvez seja esse o motivo pelo qual não chegou a perceber aquilo que a literatura mais recente sobre enfermagem já vem destacando (Fox e Messikomer, 1991), isto é, o crescimento do espaço de autonomia profissional de enfermeiras a partir da AIDS nos Estados Unidos e em outras partes do mundo - desafiando a posição subalterna das enfermeiras, típica dos hospitais desde o século XIX. Nesse sentido, devemos entender a luta das visitadoras sanitárias e, mais tarde, das enfermeiras de saúde pública pelo reconhecimento desse novo campo de conhecimento, de ciência aplicada. Assim como o médico necessita conquistar a confiança de seus clientes - mediante a resolução de problemas práticos que os afligem - o profissional de saúde pública tinha que mostrar capacidade de controlar uma área de atividade e possuir conhecimento especializado na "arte e técnica" do cuidar.

Segundo Freidson, a conquista de autonomia pelas ocupações de saúde, incluindo as "paramédicas", depende, entre outros fatores, do controle total sobre uma determinada área de trabalho "que pode estar separada do corpo principal da medicina e praticada sem o contato rotineiro ou dependência em relação à medicina". No entanto, afirmava ele, "poucas ocupações paramédicas lidam com áreas tão potencialmente autônomas". (Freidson, 1975:69) Para Freidson, mesmo uma ocupação full- 


\section{Educadoras Sanitárias e Enfermeiras}

fledged, em plena atividade, como a enfermagem, que pode ter suas próprias escolas de treinamento, seus próprios serviços em um hospital ou, ainda, controlar as instâncias de regulamentação de exercício profissional, encontra-se subordinada em autoridade, responsabilidade, autonomia e prestígio à medicina, porque boa parte de seu trabalho é exercido em clínicas e hospitais. Até as atividades realizadas em casas particulares não estão livres da supervisão dos médicos. (Id.:63-66) Para o autor,

Um de seus dilemas, entretanto, lida com o fato de que seu trabalho não pode mais ser controlado pelo seu próprio grupo ocupacional. A prática da enfermagem ocorre dentro do hospital, onde não tem encontrado autonomia. (Id.:63)

Freidson classifica como paramédicas as ocupações organizadas em torno do trabalho de cura (work of healing) e que são basicamente controladas por médicos. Esse controle é manifestado de várias formas, uma primeira refere-se à aquisição de conhecimento. Segundo o autor, grande parte do conhecimento técnico adquirido pelos "paramédicos" durante seu treinamento e, mais tarde, utilizado em seu trabalho rotineiro, passa, necessariamente, pela supervisão e aprovação dos médicos. Uma segunda forma de controle diz respeito à atuação profissional. Em geral, as tarefas de diagnóstico e tratamento são realizadas exclusivamente pelo médico. (Friedson, 1998:48-50)

Novamente, coloca-se a questão dos desafios postos pelo surgimento da AIDS. No próprio hospital - terreno em que a supremacia médica seria inconteste - as necessidades do cuidar e a impossibilidade de cura estão expandindo os espaços de legitimidade $e$ independência das profissionais enfermeiras. (Frisamos o substantivo no feminino, pois essa é uma profissão típica de recrutamento feminino). Freidson aceita que vários serviços realizados por "paramédicos" são úteis para os médicos e necessários para a sua prática, mesmo representando uma ameaça à sua autonomia. $\mathrm{O}$ autor cita o exemplo do 
farmacêutico, que vem se tornando uma ocupação competitiva em relação à prática médica, mas não explora essas situações aparentemente excepcionais, deixando de revelar suas implicações para a própria análise da autonomia, em especial para a questão de gênero.

Essas questões são especialmente sensíveis no caso da enfermagem de saúde pública, que possui graus de autonomia não previstos na formulação de Freidson. ${ }^{45}$ Mais do que enfermeiras em hospitais ou clínicas dedicadas a pacientes com moléstias crônicas, a enfermeira de saúde pública vem conquistando expressiva autonomia funcional. Em vários casos, seu trabalho pode ser executado independentemente da supervisão do médico ou de instituições - realização de exames clínicos, aplicação de vacinas, visitas domiciliares, organização de cursos em educação sanitária, diagnóstico e tratamento de doenças como a tuberculose, "consulta de enfermagem" $e$, até mesmo, prescrição de medicamentos. (cf. Barreira, 1975:76-94) Neste caso, os limites dessa autonomia são os mesmos de um médico sanitarista, quando ambos - enfermeira e sanitarista pertencem aos quadros de um serviço sanitário ou de uma secretaria de saúde. No Brasil, o trabalho da enfermagem de saúde pública, que supervisiona o Programa de Agentes Comunitários da Saúde e sua participação destacada no programa de Saúde da Família, indicam um grau de autonomia sem precedentes. Mas o trabalho das educadoras sanitárias e das enfermeiras diplomadas em saúde pública era apenas um primeiro passo na direção da conquista da autonomia profissional.

Freidson mostra que o reconhecimento profissional vinculase à organização social do campo. No caso em que as profissões de saúde organizaram seu campo, os centros de saúde foram locais privilegiados de treinamento e credenciamento -

${ }^{45}$ Devo esta observação às discussões no Seminário sobre Educação, Saúde e Sociedade na Primeira República, conduzido pelo Prof. Luiz Antonio de Castro Santos no Instituto de Medicina Social da Uerj, no segundo semestre de 2002. 


\section{Educadoras Sanitárias e Enfermeiras}

independentes, em larga medida, dos hospitais. Nos centros de saúde foram criadas condições para realização do trabalho do profissional de saúde pública, em especial, para a realização do trabalho de enfermagem em saúde pública. No entanto, era preciso mais: o apoio da sociedade e do Estado. Freidson mostra como, na organização formal de uma profissão, é imprescindível o apoio destes setores para o prestígio e o reconhecimento. (Freidson, 1998) Tomemos, novamente, o exemplo brasileiro. O período entre 1918 e início dos anos 30 foi marcado pelo maior interesse da população em relação à saúde pública e pela crescente participação do Estado na formulação e condução de políticas de saúde. Freidson diria, se fosse preocupado com a história da saúde, que tínhamos, aqui, a presença de dois ingredientes fundamentais. De um lado, a saúde pública transformou-se em questão nacional - envolvia parcelas amplas da sociedade - $e$, de outro, a atuação do Estado firmava-se na área de saneamento rural. Este cenário foi bastante favorável para o desenvolvimento da saúde pública no país e em São Paulo e criou, nesse mesmo compasso, condições favoráveis para o prestígio e o reconhecimento das profissões do campo ainda em formação e para a entrada da mulher na área da saúde. Ela foi aos poucos ampliando seu espaço de atuação, conseguindo penetrar num universo onde o poder masculino ditava as regras $e$ se fazia ainda ostensivamente presente.

Para além da questão de autonomia profissional, a rígida diferenciação de papéis sociais, atribuídos aos homens e às mulheres, foi um obstáculo para a entrada da mulher no mercado de trabalho $e$, conseqüentemente, para a conquista de sua identidade profissional. Vieira (2002) discute a ampliação do controle médico sobre a reprodução humana, nos séculos XIX e $\mathrm{XX}$ no Brasil, sugerindo que o discurso médico, nessa época, elegeu a mulher como sujeito para controlar biologicamente sua condição social. A autora trabalha com vários discursos sobre saber e práticas médicas construídas a partir de conhecimentos oriundos das áreas da higiene, medicina legal e psiquiatria, que 
utilizavam argumentos "normalizadores" sobre a função que a mulher deveria exercer no processo de formação da sociedade.

Não cabe aqui discutir questões relativas às possíveis estratégias presentes nas proposições médicas de reprodução social. No entanto, nos interessa o discurso médico de caráter higienista que, segundo a autora, entre os anos de 1870 e 1910 ganha força nos meios científicos, com objetivos sanitários de organização dos espaços urbanos. Parece difícil falar de "controle" da população, mesmo da reduzida população urbana, diante do número reduzido de facultativos e de sua precária organização de caráter associativo. ${ }^{46}$ Mas não resta dúvida de que o discurso médico da época procurava defender a importância da educação da mulher para formá-la como educadora ${ }^{47}$, enfatizando sua condição maternal. Nesse sentido, a função de reprodução parece ser menos um imperativo de ordem médica do que um preceito de caráter religioso. Preservar a infância recebe um impulso do discurso médico, mas tratava-se menos de "controlar" as mães do que de criar condições para que a unidade da família "fosse capaz de enfrentar e resolver seus problemas", como acentuava um questionário preenchido por educadoras sanitárias em São Paulo, na década de $1920{ }^{48}$

\footnotetext{
${ }^{46}$ Lembremo-nos que o primeiro evento expressivo de defesa dos direitos daquela que se denominava a "classe médica" teve lugar apenas em 1922, no Congresso dos Práticos, no Rio de Janeiro.

${ }^{47}$ As medidas higiênicas, nesta fase, teriam como meta o saneamento dos espaços públicos e a ordenação da vida familiar. Ver Vieira, 2002: 22. Ver também Costa, 1979. Para uma crítica da hipótese da higienização no século XIX, ver o trabalho de Patto, 1996.

${ }^{48}$ No serviço de visitas domiciliárias, as educadoras e enfermeiras dos centros de saúde respondiam a um minucioso questionário onde relatavam as atividades realizadas. Uma das questões indagava, textualmente: "Até que ponto a enfermeira tem contribuído para tornar a família mais capaz de enfrentar e resolver seus problemas?". Interim Report May 12, 1947 to February 25, 1950. Fundo SESP/Casa de Oswaldo Cruz, Departamento de Arquivo e Documentação/Fiocruz.
} 
Educadoras Sanitárias e Enfermeiras

Com efeito, os anos de 1920 são marcados por mudanças no discurso higienista. Se houve estratégias e normas que o discurso médico tentara impor às famílias urbanas, estas tiveram alcance limitado. A década de 1920 vai gradualmente substituindo o chamado "higienismo policial", de caráter autoritário, pela ênfase na saúde como um processo pedagógico. Mais que um discurso disciplinador sobre os corpos, a educação sanitária ajuda a promover a expansão da assistência médica às mulheres, sob uma ótica masculina, sem dúvida, mas nela o feminino não é mera estratégia de controle. A educação sanitária torna-se o projeto preponderante de organização médico-assistencial. Este cenário será extremamente propício para o campo da saúde pública em formação. As educadoras sanitárias e, mais tarde, as enfermeiras irão desempenhar um papel decisivo na assistência médica. Nesse novo papel, essas profissionais também se transformam em educadoras, assumindo atividades mais amplas. As mudanças qualitativas no discurso da higiene passam então a valorizar a necessidade de formação de novas profissionais no campo da saúde.

Nessa época, levantam-se vozes em defesa da emancipação $e$ da profissionalização da mulher através da educação. Não se reservava apenas à mulher o papel de mãe. Os papéis sociais da mulher começam a corresponder, dessa forma, às mudanças verificadas na nascente sociedade urbano-industrial brasileira.

Os padrões de trabalho específicos da enfermeira - por exemplo, a importância do cuidar junto à família - contribuíram não só para a "feminização" da profissão, mas para a conquista de um espaço de atuação e de uma área de conhecimento. Nos anos 40 e 50, a profissão - que se institucionalizava - era absolutamente feminina. As educadoras sanitárias e enfermeiras de saúde pública eram mais facilmente aceitas nos lares $e$ inspiravam a confiança das pacientes, que preferiam freqüentemente ficar sem tratamento a serem examinadas por um homem. (cf. Mott, 2000) A enfermagem de saúde pública passou a ser vista como uma profissão adequada para mulheres em função 
da sensibilidade em lidar com os cuidados do corpo da mulher e da criança. Os cuidados com o corpo feminino, considerados como competência exclusiva dos médicos no discurso oficial (não podemos esquecer do papel muito mais "normalizador" das parteiras que, especialmente no imenso Brasil rural, atendiam às parturientes), abriam espaço e geravam responsabilidades para enfermeiras e educadoras.

\section{Comentários Finais}

No Brasil, trabalhos recentes procuram refletir sobre a marcante presença de mulheres nas ciências e profissões da saúde $e$, ao mesmo tempo, tentam resgatar a trajetória de vida $e$ profissional de algumas pioneiras como Maria Augusta Generoso Estrela, Maria Antonietta de Castro, Ruth Sandoval Marcondes, Edith de Magalhães Fraenkel, entre outras. Aos poucos, essas pioneiras foram se destacando como role models e se distanciando daquela imagem construída por uma ideologia profissional que lhes negava o desempenho de atividades de cuidar e de curar. Aquelas que optaram em seguir a carreira na medicina desafiavam os valores e normas vigentes, que entendiam ser esta uma profissão masculina, imprópria para o sexo feminino. As que optavam pela carreira de educadoras ou enfermeiras viamse diante do desafio de demarcar um território de decisões e atuação, que não fosse simples "poder delegável" pela profissão médica. Essas mulheres suportaram as pressões sociais $e$ ampliaram seu espaço de atuação, se afirmando cada vez mais por meio da competência profissional e da busca de uma identidade associativa e coletiva. Na área da enfermagem, congressos $e$ associações profissionais (como a Associação Nacional de Enfermeiras Diplomadas, fundada em 1926 ${ }^{49}$ ) marcam o surgimento de uma categoria que, até nossos dias, vem conquistando um espaço de autonomia e legitimidade diante do Estado e da sociedade.

${ }^{49}$ Mais tarde, denominada Associação Brasileira de Enfermagem. 
Educadoras Sanitárias e Enfermeiras

Procuramos aqui discutir a noção de autonomia profissional como relacionada às formas especiais de organização do campo $e$ de controle do conhecimento científico pelos membros da "comunidade de visitadoras", fossem educadoras ou enfermeiras. Seguindo as considerações clássicas de Eliot Freidson (1975) e as sugestões de Geneviève Paicheler (1995), o presente estudo focalizou alguns elementos que constituem o embasamento do desenvolvimento das profissões, ou seja, a produção do saber, a conquista de autonomia profissional e o controle das práticas dirigidas à clientela. Nas palavras de Paicheler, "a questão fundamental do estudo das profissões concerne à expertise, concretizada dentro da detenção de um saber relativamente inacessível ou profano". (Paicheler, 1995:6) Mas a noção de "saber relativamente inacessível" não é facilmente associada ao saber da enfermagem, tampouco ao das educadoras. Se tomarmos o exemplo da enfermagem, tem sido mais no terreno das práticas, do que no terreno cognitivo, que essa profissão conquistou sua expertise. Talvez a enfermagem tenha conquistado menos autoridade científica do que poder social no campo da saúde, mas foi capaz de delinear um modelo de ação profissional. Para isso, suas lideranças souberam estabelecer a necessária ligação com os aparelhos de Estado e contaram, no Brasil, com o apoio da Fundação Rockefeller - cujo modelo de atuação privilegiou o status profissional de todas as categorias no campo biomédico.

No caso da educadora e da enfermeira de saúde pública, os padrões de trabalho específicos da atividade - por exemplo, a importância do cuidar junto a pacientes tuberculosos, ou, em nossos dias, nos programas de saúde da família e junto a pacientes terminais -, ainda que não definissem uma nova "ciência", propunham, desde seus primeiros tempos, um olhar independente sobre o doente, sua família e sua comunidade $e$ abriram caminho para as conquistas atuais da saúde comunitária $e$ da saúde da família. Desde os tempos do surgimento da enfermagem profissional no Brasil, há mais de 80 anos, a forte "feminização" da profissão coloca interessantes desafios para a 
discussão política e sociológica: além de não constituir uma profissão subalterna, por "razões de gênero", vem se firmando no espaço das ciências da saúde e das profissões e tem atraído um contingente masculino expressivo. Os novos colegas sabem estar diante de uma atividade de ensino e de um desempenho profissional controlados, em grande parte e com indiscutível êxito, por mulheres.

\section{Referências bibliográficas}

BARREIRA, Ieda de Alencar e SANTOS, Tânia Cristina Franco. A Escola Anna Nery como centro difusor de tradições nativas. Escola Anna Nery. Revista de Enfermagem 3 (2), 1999, Rio de Janeiro, pp.18-33.

BARREIRA, I. A. A Enfermeira-Ananéri no "País do Futuro"; a aventura da luta contra a tuberculose. Tese de Doutorado, Rio de Janeiro, Escola de Enfermagem Anna Nery, 1992.

. Estudo exploratório sobre a consulta de enfermagem. Revista Brasileira de Enfermagem (28), Rio de Janeiro, 1975, pp.76-94.

CAMPOS, Cristina de. São Paulo pela lente da higiene. As propostas de Geraldo de Paula Souza para a cidade (1925-1945). São Carlos, RiMa Editora, 2002.

Evolução histórica da educação em saúde pública como disciplina de ensino na Faculdade de Saúde Pública da Universidade de São Paulo (1925-1967). Revista de Saúde Pública 22(4), São Paulo, Faculdade de Saúde Pública/USP, 1988, pp.347-365.

- Memória histórica da Faculdade de Saúde Pública da Universidade de São Paulo (1918/1954). Revista de Saúde Pública, vol. 18, nº especial, São Paulo, 1984, pp.2-60.

CASTRO SANTOS, Luiz A. de e FARIA, Lina. A Cooperação Internacional e a Enfermagem de Saúde Pública no Rio de Janeiro e São Paulo. Horizontes, vol. 22 (2), Bragança Paulista, CDAPH-Universidade São Francisco, julho/dezembro de 2005, pp.123-148.

- A reforma sanitária no Brasil: Ecos da Primeira República. São

Paulo, Editora da Universidade São Francisco, 2003. 
Educadoras Sanitárias e Enfermeiras

. Os primeiros centros de saúde nos Estados Unidos e no Brasil: um estudo comparativo. Teoria e Pesquisa, ns 40/41, São Paulo, Editora da Universidade Federal de São Carlos, 2002, pp.137-181.

CHAGAS, Carlos. A enfermeira moderna. Apelo às moças brasileiras. Rio de Janeiro, Oficinas Gráficas da Inspetoria de Demografia Sanitária, Educação e Propaganda/Departamento Nacional de Saúde Pública, 1922, pp.1-10.

CHAGAS, Evandro. Enfermagem em face do problema rural do Brasil. Annaes de Enfermagem, ano 6 (15), 1938, pp.5-7.

COLLIER, Peter e HOROWITZ, David. The Rockefellers: An American Dynasty. Broadway, New York, New American Library, 1976, pp.6165.

CORTEZ, Adamastor. Centros de saúde de São Paulo. Tese de doutorado, São Paulo, Faculdade de Medicina de São Paulo, 1926.

COSTA, Jurandir Freire. Ordem médica e norma familiar. Rio de Janeiro, Graal, 1979.

CUETO, Marcos. Missionaries of Science. The Rockefeller Foundation and Latin America. Bloomington/Indianápolis, Indiana University Press, 1994.

DAVIES, Celia. Professionalizing Strategies as Time-and Culture-Bound: American and British Nursing, Circa 1893. LAGEMANN, Ellen Condliffe. (ed.) Nursing History. New Perspectives, New Possibilities. New York/London, Teachers College, Columbia University, 1983.

FARIA, Lina. Saúde, política e cooperação internacional: A Fundação Rockefeller e seus parceiros em São Paulo (1918-1951). Rio de Janeiro, Editora Fiocruz, 2006, no prelo.

. A Fundação Rockefeller e os serviços de saúde em São Paulo (1920-30): perspectivas históricas. História, Ciências, Saúde: Manguinhos, vol. IX (3), Rio de Janeiro, Editora Fiocruz, setembro/ dezembro de 2002, pp.561-590.

. Scientific Traditions in Brazil: The History of the Instituto de Higiene in São Paulo. Rockefeller Archive Center Research Reports Online, New York, Tarrytown, 2001, pp.1-6.

. O Instituto de Higiene: contribuição à história da ciência e da administração em saúde em São Paulo. Physis - Revista de Saúde Coletiva, vol. IX (1), Rio de Janeiro, IMS, 1999, pp.175-208. 
FREIDSON, Eliot. Renascimento do profissionalismo. São Paulo, Editora da USP, 1998 (Trad.: Celso Mauro Paciornik).

. Profession of Medicine. A Study of the Sociology of Applied Knowledge. New York. Dodd, Mead \& Company. 1975.

GOLDMARK, Josephine. Nursing and nursing education in the United States. New York, The Macmillan Company, 1923.

HOWE, Barbara. The emergence of scientific philanthropy, 1900-1920: Origins, issues and outcomes. Philanthropy and cultural imperialism: The foundations at home and abroad. $2^{\mathrm{a}}$ ed. Bloomington, Indiana University Press, 1982, pp.25-54.

LEIBOWITZ, Lila. Perspectives on the evolution of sex differences. Toward an Anthropology of Women. New York/London, Monthly Review Press, 1975, pp.20-35.

MARINHO, Maria Gabriela S.M.C. Norte-americanos no Brasil. Uma história da Fundação Rockefeller na Universidade de São Paulo (1934-1952). Campinas/São Paulo, Autores Associados/Universidade São Francisco, 2001.

MASCARENHAS, Rodolfo dos Santos e FREITAS, Adélia Vieira de. Contribuição ao estudo da história do ensino de educação sanitária na Faculdade de Higiene e Saúde Pública da Universidade de São Paulo. Arquivos da Faculdade de Higiene e Saúde Pública, 13 (1), São Paulo, USP, 1959.

MOTT, Maria Lúcia de Barros. Maria Renotte, uma médica paulista no início do século. Médicis: cultura, ciência e saúde, ano 2 (7), 2000.

Revendo a história da enfermagem em São Paulo (18901920). Cadernos Pagu (15) - Gênero, Ciências, História -, Núcleo de Estudos de Gênero - Pagu/Unicamp, 1999, pp.327-355.

PAICHELER, Geneviéve. Présentation. Les professions de soins: territoires et empiètements. Sciences Sociales et Santé, vol. 13 (3), Paris, Editions John Libbey Eurotext, 1995, pp.5-10.

PATTO, Maria Helena Souza. Teoemas e cataplasmas no Brasil Monárquico: o caso da Medicina Social. Novos Estudos Cebrap 44, São Paulo, março de 1996, pp.180-199.

PAULA SOUZA, Geraldo Horácio de e BORGES VIEIRA, Francisco. Formação de técnicos para os serviços de saúde pública. Revista de Higiene e Saúde Pública, ano VI (1), 1948, pp.1-35. 
Educadoras Sanitárias e Enfermeiras

. Centros de saúde. "Eixo" da organização sanitária. Boletim do Instituto de Higiene ${ }^{\circ}$ 59, São Paulo, Imprensa Oficial do Estado de São Paulo, 1944, pp.1-50.

RAGO, Elisabeth Juliska. A ruptura do mundo masculino da medicina: médicas brasileiras no século XIX. Cadernos Pagu (15), Núcleo de Estudos de Gênero - Pagu/ Unicamp, 2000, pp.199-225.

RENÉE C. Fox, AIKEN, Linda e MESSIKOMER, Carla. The culture of caring: AIDS and the nursing profession. In: Nelkin, D.; Willis, D.P. \& Parris, S. (eds.) A disease of society: Cultural and institutional responses to AIDS. Cambridge University Press, 1991.

ROCHA, Heloísa Helena Pimenta. A higienização dos costumes. Educação escolar e saúde no projeto do Instituto de Higiene de São Paulo (1918-1925). Campinas/São Paulo, Mercado das Letras/ FAPESP, 2003.

ROHDEN, Fabíola. $A$ arte de enganar a natureza. Contracepção, aborto $e$ infanticídio no início do século XX. Coleção História e Saúde. Rio de Janeiro: Editora Fiocruz, 2003.

Uma ciência da diferença: sexo e gênero na medicina da mulher. Rio de Janeiro, Editora Fiocruz, 2001.

ROSEN, George. A history of public health. New York, MD Publications, INC., 1976.

SCHULTHEISS, Katrin. Class, gender and Professional identity. Bodies and Souls. Politics and the professionalization of nursing in France, 1880-1922. London/Massachusetts, Harvard University Press/ Cambridge, 2001.

VASCONCEllos, Maria da Penha C. (coord.) Memórias da saúde pública: a fotografia como testemunha. São Paulo/Rio de Janeiro, Editora HUCITEC/ABRASCO, 1995, pp.1-110.

VIEIRA, Elisabeth Meloni. A medicalização do corpo feminino. Rio de Janeiro, Editora Fiocruz, 2002. 